\section{Steady-State Dissolution Kinetics of Aluminum-Goethite in the Presence of Desferrioxamine-B and Oxalate Ligands}

\author{
JAVIERA CERVINI-SILVA* AND \\ GARRISON SPOSITO
}

Division of Ecosystem Sciences, University of California, Hilgard Hall, Room 3110, Berkeley, California 94720-3110

This paper reports steady-state dissolution rates of synthetic low-substitution Al-goethites (mol \% Al < 10) at $\mathrm{pH} 5$ in the presence of the trihydroxamate siderophore, desferrioxamine $B$ (DFO-B), and the common biological ligand, oxalate. The siderophore-promoted Fe release rate increased both with the level of Al substitution and with DFO-B concentration up to about $100 \mu \mathrm{M}$, after which a plateau occurred, suggesting a saturation effect from DFO-B adsorption as a precursor to dissolution. At concentrations above $200 \mu \mathrm{M}$, oxalate also enhanced the Fe release rate, which however was not influenced by Al substitution. For Al-goethites with $\mathrm{mol} \% \mathrm{Al}<4$, the Fe release rate in the presence of $40 \mu \mathrm{M}$ DFO-B together with varying concentrations of oxalate was typically greater than the corresponding sum of dissolution rates in the presence of the two ligands alone. This synergism may be the combined result of the ability of oxalate to adsorb strongly at the goethite surface, thus promoting Fe release, and of the high selectivity of DFO for Fe(III). Ferric oxalate complexes formed during dissolution will likely lose $\mathrm{Fe}^{3+}$ by ligand substitution with DFO-B, leading to the production of Fe(HDFO-B $)^{+}$and uncomplexed oxalate, the latter of which, in turn, could adsorb to the goethite surface again. For Al-goethites with mol \% Al > 4, synergism was not apparent, which may signal the effect of a decreased surface density of $\mathrm{Fe}-\mathrm{OH}$ sites associated with Al for Fe substitution. The oxalate-promoted release rates of $\mathrm{Al}$ did not scale with those of $\mathrm{Fe}$, indicating incongruent dissolution. However, Al release rates in the presence of DFO-B did scale approximately with those of Fe but were not affected by the concentration of siderophore. These results are consistent $w$ ith the presence of $\mathrm{Al}(\mathrm{OH})_{3}$ inclusions in Al-goethite.

\section{Introduction}

Goethiteformed in terrestrial weathering environments often exhibits Al substitution for $\mathrm{Fe},\left[\mathrm{Fe}_{1-x} \mathrm{Al} \times \mathrm{OOH}\right.$, with $\mathrm{Al}$ content up to $x=0.33$ (1). X-ray diffraction analyses of more than 200 South African soil samples collected by Fitzpatrick and Schwertmann (2) indicated the predominance of goethite with low Al content $(x<0.15)$ in hydromorphic environments. This level of substitution, characteristic of variable redox

\footnotetext{
* Correspondingauthor phone: (510)643-9951; fax: (510)643-2940; e-mail: jcervini@nature.berkeley.edu.
}

conditions at circumneutral $\mathrm{pH}$, alters crystal size, texture, domain morphology, surfacearea, structural strain, and other structural properties $(1,3)$ that influence the rates and mechanisms of goethite dissolution. Schwertmann and coworkers $(4,5)$ have reported that low Al substitution for Fe in goethite also leads to a decrease in proton- and ligandpromoted reductive dissolution rates, concluding that this occurs because of an increasein disorder of the crystals within interdomains, leading to fewer structural defects that promote abiotic dissolution (1).

A recent study of the microbial reductive dissolution of synthetic Al-goethites ( $x=0,0.051$, and 0.33 ) by Clostridium butyricum, an Fe-reducing bacterium isolated from an oxisol, showed incongruent dissolution of $\mathrm{Al}$ and $\mathrm{Fe}$, unlike abiotic reductive dissolution, and a decrease in the rate of Fe release by reductive dissolution as Al substitution increased (6). The decreasein Fereleaseratewas attributed to theaccumulation of Al at the goethitesurface resulting in theblocking of reactive sites during enzymatic reduction. However, another study of the microbial reductive dissolution of a natural Al-goethite sample $(x=0.17 ; 7)$ by Shewanella putrefaciens found that Al sorption had no effect on dissolution. This latter result was explained by Al adsorption or precipitation at surface sites distant from those where reductivedissolution occurred.

Thebacterially mediated dissolution of Al-goethite in oxic environments also has been investigated recently. Samples of synthetic Al-substituted goethite $(0 \leq x \leq 0.088)$ incubated under batch conditions (8) with siderophore-producing bacteria (Pseudomonas mendocina var.) showed microbial release of Fe that was inversely related to the particle aspect ratio and, therefore, increased with increasing Al content, in contrast with reductive dissolution. Evidently, Al substitution leads to an increase in the population of reactive sites available for microbially mediated dissolution under oxic conditions. Under reducing conditions, theoppositeappears to be true. For example, in the dissolution of goethite by $\mathrm{C}$. butyricum (6), although the number of electrons produced by glucose fermentation in the presence of Al-goethite was comparable to the number produced in the presence of unsubstituted goethite, the percentage use for Fe(III) reduction was $5.7 \%$ for unsubstituted goethite, but only 1.6 and $0.55 \%$ for Al-goethites with $x=0.05$ and 0.33 , respectively. Thus, the number of ferric reduction sites, not metabolic activity, appeared to limit the release of Fe during the reductive dissolution of Al-goethite.

Aluminum substitution has been shown to affect the release of Fefrom goethite during either microbially mediated (6-8) or ligand-promoted (1) dissolution, but the details of surface-organic interactions associated with these processes remain unexplored. Of particular interest for the presentstudy is the fact that, although the biotic dissolution of Fe(III)bearing minerals under oxic conditions is accompanied by the production of siderophores $(9,10)$, little quantitative information exists about their specific rolein the dissolution process. In pioneering experiments with unsubstituted goethite, Watteau and Berthelin (9) demonstrated the remarkable efficacy of the common trihydroxamate siderophore, desferrioxamine B (DFO-B), in promoting the solubilization of $\mathrm{Fe}$, when compared to either protons or other common biological ligands, such as oxalate. They attributed this difference to the Fe(III)-specific complexing ability of the siderophore. Similarly, Kraemer et al. (11) reported an enhanced rate of Fe release from goethite in the presence of DFO-B, concluding that coordination of the siderophore to an Fe(III) center at the mineral surface is a precursor to the dissolution process, a mechanistic step also suggested by

VOL. 36, NO. 3, 2002 / ENVIRONMENTAL SCIENCE \& TECHNOLOGY = 337 
TABLE 1. Properties of the Al-Goethite Samples

\begin{tabular}{|c|c|c|c|c|c|}
\hline sample & $\begin{array}{c}\mathrm{mol} \% \mathrm{Al}^{\mathrm{a}} \\
(=100 \times)\end{array}$ & $\begin{array}{c}a_{s}^{b} \\
\left(m^{2} g^{-1}\right)\end{array}$ & $\begin{array}{c}\ln K^{c} \\
\left(K \text { in } \min ^{-1}\right)\end{array}$ & $\alpha^{c}$ & $\begin{array}{c}\ln k^{c} \\
\left(k \text { in } \min ^{-1}\right)\end{array}$ \\
\hline $\begin{array}{l}\text { S1 } \\
\text { S2 } \\
\text { S3 } \\
\text { S4 }\end{array}$ & $\begin{array}{c}2.6 \pm 0.7 \\
3.6 \pm 1.2 \\
4.5 \pm 1.1 \\
10 \pm 2\end{array}$ & $\begin{array}{l}46.8 \pm 3.9 \\
44.9 \pm 3.8 \\
39.5 \pm 3.4 \\
37.0 \pm 3.2\end{array}$ & $\begin{array}{r}-7.76 \pm 0.98 \\
-7.76 \pm 0.59 \\
-10.15 \pm 1.55 \\
-11.85 \pm 1.85\end{array}$ & $\begin{array}{l}1.22 \pm 0.14 \\
1.06 \pm 0.09 \\
1.32 \pm 0.21 \\
1.41 \pm 0.22\end{array}$ & $\begin{array}{l}-6.3 \pm 0.3 \\
-6.7 \pm 0.2 \\
-7.7 \pm 0.3 \\
-8.5 \pm 0.3\end{array}$ \\
\hline
\end{tabular}

a Measured by $\mathrm{HCl}$ digestion of the Al-goethite samples. Determinations of $\mathrm{Al}$ and Fe in triplicate for each of two samples of $\mathrm{Al}$-goethite. ${ }^{b}$ Measured by the static BET method; mean \pm standard deviation. ${ }^{c}$ Parameters in eq 2 (time in min) with $P=0.05$ confidence intervals.

Holmén and Casey $(12,13)$ and by Kalinowski et al. (10) in their studies of the kinetics of hydroxamate-promoted mineral dissolution.

Organic ligands of small size and low molecular mass commonly found in soils, such as oxalate, may also enhance the dissolution of goethite (e.g., ref 14). How the presence of oxalate, DFO-B, or both ligands affects Ferelease following dissolution remains largely unknown. Cheah et al. (15) very recently haveshown that the dissolution rate of unsubstituted goethite at $\mathrm{pH} 5$ in the presence of DFO-B ([DFO-B] $\leq 80$ $\mu \mathrm{M})$ was doubled in the presence of oxalate $([\mathrm{Ox}]=29$ or 40 $\mu \mathrm{M})$, whereas the dissolution rate in the presence of oxalate $([\mathrm{OX}]=0-200 \mu \mathrm{M})$ was increased by an order of magnitude when DFO was present at $40 \mu \mathrm{M}$ solution concentration. These results were thought to imply that if DFO-B were present at large enough concentration to complex all dissolved $\mathrm{Fe}(\mathrm{III})$ released by oxalate-promoted goethite dissolution, it could displace oxalate from $\mathrm{Fe}$-oxalate complexes that may have formed and, as a result, enable the uncomplexed oxalate ligand to react again with the goethite surface. The resulting synergy in the two-ligand system then suggests that the production of siderophores in the presence of low concentrations of oxalate would be an extremely effective mechanism for the microbial acquisition of Fefrom goethite.

In this paper, we extend the study of Cheah et al. (15) to dissolution experiments with low-substitution Al-goethite $(x<0.1)$ at $\mathrm{pH} 5$ in the presence of both the trihydroxamate siderophore DFO-B and the ubiquitous biological ligand oxalate. The objective of our experiments was to quantify the dissolution kinetics of Al-goethite as influenced by the siderophore, by oxalate, and by the two ligands in combination under steady-state conditions. A broad range of concentrations of the two ligands was utilized $(20-1000 \mu \mathrm{M})$ to encompass their expected concentrations in soil solutions (9).

\section{Experimental Section}

Materials. Perchloric acid (70\%), sodium hydroxide (1 M), aluminum nitrate $(99+\%)$, ferric nitrate $(99 \%)$, potassium hydroxide (99\%), and hydrochloric acid (30\%) werepurchased from Fisher (Fair Lawn, NJ). Sodium perchlorate (ACSgrade) was purchased from GFS (Columbus, OH); oxalic acid (99+\%) was purchased from Aldrich (Milwaukee, WI). 2-(N-Morpholino)ethanesulfonic acid buffer (MES) was purchased from Sigma (St. Louis, MO). I ron and aluminum ICP standard solutions were purchased from Ultra Scientific (North Kingston, RI). Desferrioxamine B (DFO-B) was produced by Ciba-Geigy (Desferal) and received as a gift from Salutar Corporation. In all experiments, solutions were prepared with high-purity $18 \mathrm{M} \Omega \cdot \mathrm{cm}$ water (Milli-Q Plus, Millipore, Ann Arbor, MI).

Synthesis. Four samples of Al-substituted goethite (S1S4) were synthesized as described in Schwertmann and Cornell (3). Fresh solutions of $1 \mathrm{M} \mathrm{Fe}\left(\mathrm{NO}_{3}\right)_{3}, 0.5 \mathrm{M} \mathrm{Al}\left(\mathrm{NO}_{3}\right)_{3}$, and $5 \mathrm{M} \mathrm{KOH}$ were prepared. An aluminate solution was prepared by adding $500 \mathrm{~mL}$ of $\mathrm{Al}\left(\mathrm{NO}_{3}\right)_{3}$ and $300 \mathrm{~mL}$ of $\mathrm{KOH}$ solutions at constant stirring. Aliquots of al uminate solution $(20,40,80$, and $120 \mathrm{~mL}$, respectively) were poured into $2-\mathrm{L}$ polypropylene bottles followed by $178,176,170$, and $165 \mathrm{~mL}$ of $\mathrm{KOH}$ stock solution. Immediately after that, $100 \mathrm{~mL}$ of the $\mathrm{Fe}\left(\mathrm{NO}_{3}\right)_{3}$ stock solution was added to each bottle and made up to $2 \mathrm{~L}$ with twice-distilled water. The polyethylene tubes were mixed for $10 \mathrm{~min}$ and placed in an oven at $70^{\circ} \mathrm{C}$ for 14 days. The bottles wereshaken once a day. After crystallization was complete(as indicated by a compact yel low precipitate), the samples were centrifuged, and the product was washed twice with $400 \mathrm{~mL}$ of $1 \mathrm{M} \mathrm{KOH}$ to remove extra Al. The $\mathrm{pH}$ of the supernatant solution was adjusted to 7.5 with $1 \mathrm{M} \mathrm{HCl}$, washed with twice-distilled water, freeze-dried, and stored in polyethylene bottles. These four samples will be referred to as S1-S4. Powder X-ray diffraction (Cu K $\alpha$ ) confirmed the four synthesized solids as Al-goethites (data not shown) with characteristic peaks assigned to the 110, 120, 130, 111, 140, $221,151,250$, and 061 planes. The progressive shifting of the $130,061,221$, and 120 peaks to lower d values with increasing sample number confirmed an increasing substitution of Fe by $\mathrm{Al}(1,16)$. Additional confirmation of Al substitution was provided by ATR-FTIR spectra of the samples (data not shown), which displayed a blue-shift of the $\mathrm{OH}$ bending vibrational bands with increasing samplenumber, typical of increasing Al content $(1,3)$.

Characterization of the Al-Goethite Samples. The nominal Al content of the Al-goethite samples was determined from acid digestion (Table 1$)$. Specific surface area $\left(a_{s}\right)$ determinations on the goethite samples were performed by the static BET method using $\mathrm{N}_{2}$ gas. In addition, $\mathrm{HCl}$ dissolution kinetics studies were conducted to characterize Al substitution and crystallinity (17) in the four Al-goethite samples.

$\mathrm{HCl}$ Digestion. Aluminum determination by complete dissolution in concentrated $\mathrm{HCl}$ was performed as described by Schwertmann $(3,18)$. A total of $100 \mathrm{mg}$ of Al-goethite sample was incubated with $20 \mathrm{~mL}$ of $12 \mathrm{~N} \mathrm{HCl}$ at $80^{\circ} \mathrm{C}$ for 20-40 min or until total dissolution was achieved. The solutions were diluted 1:100 with acidified twice-distilled water $(10 \% \mathrm{HCl})$ and analyzed for $\mathrm{Al}$ and Fe using an inductively-coupled plasma atomic emission spectrometer (ICP-AES, Thermo Jarrel Ash) with emission lines at 396.1 and $238.2 \mathrm{~nm}$, respectively.

$\mathrm{HCl}$ Dissolution Kinetics. Acid dissolution kinetics studies of the Al-goethite samples were conducted as described by Schwertmann (4). Briefly, 250-mg samples of goethite were dissolved in $250 \mathrm{~mL}$ of $6 \mathrm{M} \mathrm{HCl}$ at $24^{\circ} \mathrm{C}$ with constant shaking. Subsamples of the reaction mixture were taken at intervals over a period of $72 \mathrm{~h}$ or until total dissolution was achieved and then centrifuged. Thesupernatant solution was decanted and filtered prior to Fe analysis using ICP-AES at $238.2 \mathrm{~nm}$.

The fraction of Fe dissolved was plotted as function of reaction time for each of the samples, where "fraction of Fe dissolved" refers to the amount of Fe dissolved at a time $t$ relative to theamount of Fedissolved att $=72 \mathrm{~h}$. Theresulting S-shaped dissolution curves (not shown) were modeled, similar to a large number of dissolution experiments on iron oxides (ref 1, p 296), by the Kabai (19) equation, based on 
the concentration-time relationship:

$$
C(t)=1-e^{-K t \alpha}
$$

or in log-transform linearized form:

$$
\ln [\ln \{1 /(1-C)\}]=\ln K+\alpha \ln t
$$

where $\mathrm{C}(\mathrm{t})$ is the fraction of Fe dissolved at timet, and $\mathrm{K}$ and $\alpha$ are empirical constants. The regression parameters (In K, $\alpha)$ and the dissolution rate constant $k[k=(1 / \alpha)$ In K $]$ found for the four samples are listed in Table 1 (ANOVA with 95\% confidence intervals).

Determination of Al content using the Vegard rule (20) based on the two strongest XRD reflections, $d(110)$ and $d(111)$, as calculated from the diffractograms of samples S1-S4, and the c-dimension of the unit cell was considered but not included becausetheAl content must differ between samples by at least $5.2 \mathrm{~mol} \% \mathrm{Al}(20)$ to bedistinguished by this method.

Ligand-Promoted Dissolution Kinetics. Continuous-flow stirred-tank reactors (CFSTR) were used to study dissolution (oneAl-goethitesample per reactor) in the presence of DFO-B and oxalate ligands. The CFSTR apparatus (Cole-Parmer, Catalogue No. E-02910-41) was similar to that described by Kraemer and Hering (21). The body of the reactor was made from Plexiglass, while the cap and bottom were made from Delrin. The volume of the reactor was $69.5 \pm 0.2 \mathrm{~mL}$. Cellulose-acetate (Millipore) filters $(0.025 \mu \mathrm{m})$ were placed at the bottom of each reactor before adding goethite $(0.69$ $\mathrm{g}$ ); the reactors were then filled with distilled water, such that the final suspension contained $10 \mathrm{~g} \mathrm{~L}^{-1}$ goethite. The reactors were closed, and Tygon tubing (replaced monthly) was used to connect the reactors with the corresponding influent and effluent solution containers. Special caution was taken to prevent the formation of air bubbles in the reactors and Tygon lines. Theflow rateof theinfluent solution was controlled using a peristaltic pump (Masterflex), and the reactors werestirred at constant speed of about $500 \mathrm{rpm}$.

The influent solution was adjusted to $\mathrm{pH} 5$ by adding aliquots of $\mathrm{HNO}_{3}$ or $\mathrm{NaOH}$ stock solution. Its composition was $0.01 \mathrm{M} \mathrm{NaClO}_{4}, 5 \mathrm{mM}$ MES buffer, oxalate $(0-1000 \mu \mathrm{M})$, and/or DFO-B $(0-2000 \mu \mathrm{M})$. To promotedissolution of labile $\mathrm{Fe}$, theAl-goethitesamples were preconditioned with influent solution at $\mathrm{pH} 5$ containing $20 \mu \mathrm{M}$ DFO-B for $400 \mathrm{~h}$ or until the Fe concentration in the effluent solution was observed to be invariant over time. During pretreatment, non-steadystateconditions prevailed, wherein dissolved concentrations of DFO-B and Fe varied continuously. The difference in the influent and effluent DFO-B concentrations was very small, indicating that very little DFO-B (if any) had become irreversibly bound to the goethite surface. Then the concentration of the influent DFO-B was reduced to zero, and the samples were equilibrated for an additional $120 \mathrm{~h}$. Thereafter, the dissolution kinetics of the goethite samples were studied as function of the concentration of DFO-B or oxalate added initially to the influent suspension, namely, $[\mathrm{DFO}]_{0}$ or $[\mathrm{Ox}]_{0}$, respectively. A third set of experiments was performed to study the effect of [Ox] on the dissolution of Al-goethites by $[\mathrm{DFO}]_{0}$, with $[\mathrm{DFO}]_{0}=40 \mu \mathrm{M}$ and $[\mathrm{Ox}]_{0}$ varied from 0 to $1000 \mu \mathrm{M}$. Proton activity was measured with a Ross combination electrode calibrated with buffer solutions at $\mathrm{pH} 4, \mathrm{pH} \mathrm{7}$, and $\mathrm{pH} 10$.

The entire system, including influent and effluent solution containers, lines, and pumps, was covered with aluminum foil. Samples of the effluent solution of each reactor were collected twice per day in disposable polyethylenetubesand stored at $5{ }^{\circ} \mathrm{C}$ for $\mathrm{Fe}$ and $\mathrm{Al}$ determination using ICP-AES. Standard curves, freshly prepared, were used for the quantitation of Fe and Al. A third sample was collected daily to measure the effluent flow rate.
The dissolution rate of Al-goethite (R), determined after steady values of the Feconcentration in the effluent solution were observed (>500 h), was calculated as

$$
\mathrm{R}=60[\mathrm{Fe}]_{\mathrm{eff}} \frac{\mathrm{q}}{\mathrm{m}}
$$

where $[F e]_{\text {eff }}$ is the concentration of Fein the effluent solution $(\mu \mathrm{M})$ under steady-state conditions, $\mathrm{q}$ is the effluent flow rate $\left(\mathrm{mL} \mathrm{min}^{-1}\right)$, and $\mathrm{m}$ is the mass of goethite $(\mathrm{g})$. The resulting units of $R_{L}$ are then $n m o l ~ ~ g^{-1} h^{-1}$. (The number 60 in eq 3 serves to convert the rate to an hourly basis). Typical effluent flow rates ranged between 0.08 and $0.16 \mathrm{~mL} \mathrm{~min}^{-1}$. The value of [Fe $]_{\text {eff }}$ used was the average of replicate values of Fe concentration (10 per experiment) measured in the collected samples. Conventional statistical analysis was performed to test for outliers (22). Any [Fe] $]_{\text {eff }}$ values suspected as outliers were discarded when they differed by more than twice the standard deviation from the average [Fe] $]_{\text {eff }}$ based on all of the remaining values determined in an experiment. The smallest value of [Fe $]_{\text {eff }}$ detectable was about $0.01 \mu \mathrm{M}$, which leads to a minimum detectable dissolution rate of approximately $0.1 \mathrm{nmol} \mathrm{g}^{-1} \mathrm{~h}^{-1}$.

The measured dissolution rate of goethite in the presence of DFO-B and oxalate together, $\mathrm{R}_{\mathrm{DFO}-\mathrm{Ox} \text { obs, }}^{\mathrm{Fe}}$ was compared to the sum of dissolution rates of goethite in the presence of DFO-B only or oxalate only, R Re $\mathrm{Fe}$-Ox sum, by using conventional statistical analysis (22) to test for significant difference $(P=0.05)$.

\section{Results and Discussion}

The $\mathrm{HCl}$ dissolution curves (not shown) of the Al-goethite sampleswereS-shaped, whilethe dissolution rate decreased and the shape of the curve became increasingly sigmoidal with increasing Al for Fe substitution, as also described by Schwertmann $(1,4,18)$. Electron micrographs $(23)$ of a series of low-substitution Al-goethites $(x<0.1)$ before and after dissolution in $6 \mathrm{M} \mathrm{HCl}$ at $24^{\circ} \mathrm{C}$ revealed increases in surface area during the initial stages of dissolution and preferential dissolution of less-ordered portions of the goethite crystals. The shapes of the dissolution curves for samples S1-S3 were consistent with the concept that surface defects and interdomain boundaries may be exposed by etching during the initial stages of dissolution $(18,24)$ and, as result, increase the surface area available to proton-promoted dissolution. The dissolution curve for sample S4 had a pronounced sigmoidal shape, which could be because of decreased surface density of $\mathrm{Fe}-\mathrm{OH}$ sites (24) following Al for Fe substitution in goethite.

Table 1 shows that the dissolution rate constant $k$ (eq 2) decreased with increasing Al content, in agreement with the well-known observation that Al substitution decreases protonpromoted dissolution $(1,4)$. The decreasein $\mathrm{k}$ with a decrease in surface area (Table 1) would suggest that the acid dissolution of samples S1-S4 is surface-controlled. Figure 1 shows that the dissolution rate per unit surface area $\left(\mathrm{k} / \mathrm{a}_{\mathrm{s}}\right)$ also tends to decrease with increasing Al substitution, in good agreement with data for synthetic goethite samples and Fe-rich goethitic/ hematitic tropical soils (4). The results shown in Figure 1 can be explained by considering the combined effect of surface area and Al substitution on the dissolution of samples S1-S4, as described by Ruan and Gilkes (24). Aluminum substitution in goethite leads to a reduction in crystal size and surface area, but acid digestion of Al-goethitefavors the cleavage of $\mathrm{Fe}-\mathrm{O}$ bond(s) morethan Al bond(s). Figure 1 thus indicates the dominance of the effect of the greater strength of the $\mathrm{Al}-\mathrm{O}$ bond in the acid dissolution of samples S1-S4.

Ligand-Promoted Dissolution. The Fe rel ease rate from Al-goethite ( $\mathrm{R}_{\mathrm{DFO}}^{\mathrm{Fe}}$, Figure 2 and Table 2 ) increased as the 


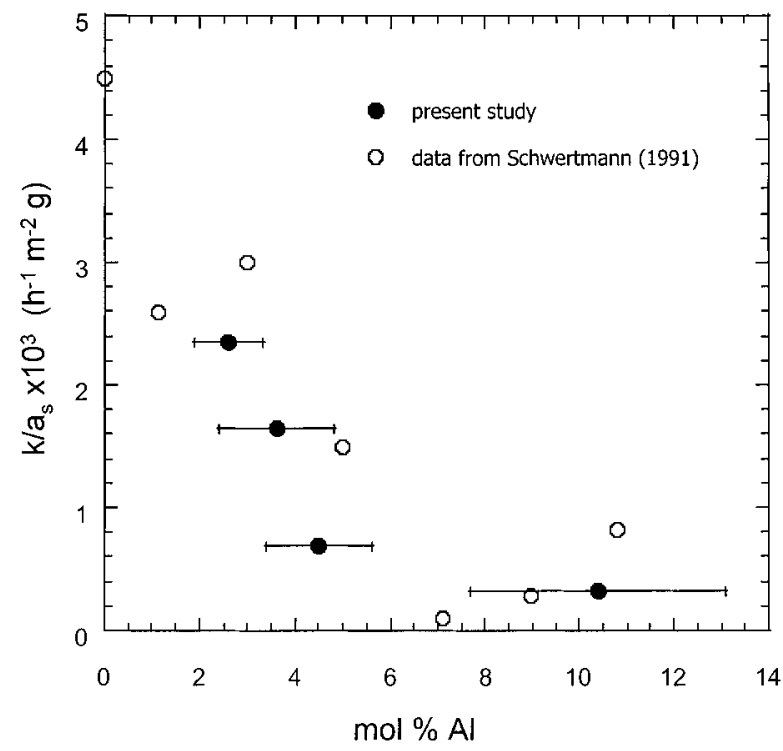

FIGURE 1. Comparison of area-normalized dissolution rate constants as a function of Al substitution for samples S1-S4 (O) with the same data for soil goethites $(O ; 4)$.

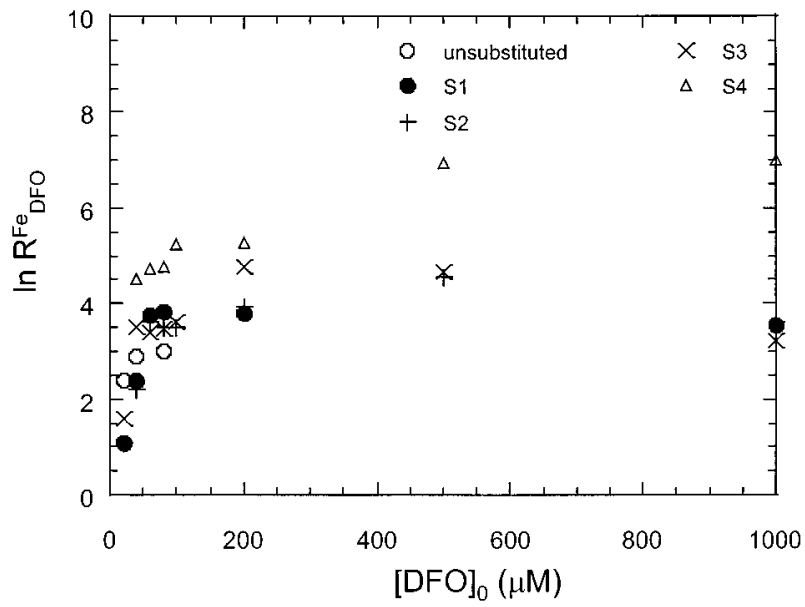

FIGURE 2. Steady-state dissolution rates $\left(R_{\mathrm{DFO}}^{\mathrm{Fe}}\right.$ in $\left.\mathrm{nmol} \mathrm{g}^{-1} \mathrm{~h}^{-1}\right)$ of unsubstituted goethite $(O)$ and Al-goethite samples S1 (O), S2$(+)$, S3 $(\times)$, and S4 $(\triangle)$ plotted as a function of the concentration of DFO-B (Table 2).

TABLE 2. Steady-State DFO-Promoted Dissolution Rates ${ }^{a}$

\begin{tabular}{ccrrrr} 
& \multicolumn{5}{c}{ sample } \\
\cline { 2 - 6 }${\text { [DFO-B }]_{0}(\boldsymbol{\mu} \text { M) }}$ & unsubstituted $^{b}$ & S1 $^{\boldsymbol{c}}$ & S2 $^{\boldsymbol{c}}$ & S3 $^{\boldsymbol{c}}$ & S4 $^{\boldsymbol{c}}$ \\
20 & 11 & 3 & 3 & 5 & 3 \\
40 & 18 & 11 & 9 & 33 & 92 \\
60 & $\ldots d$ & 43 & 38 & 30 & 114 \\
80 & 20 & 46 & 34 & 32 & 117 \\
100 & $\ldots$ & $\ldots$ & 34 & 38 & 190 \\
200 & $\ldots$ & 45 & 51 & 117 & 200 \\
500 & $\ldots$ & $\ldots$ & 94 & 107 & 1039 \\
1000 & $\ldots$ & 35 & 37 & 25 & 1129
\end{tabular}

a $R$ DFO in nmol g-1 $\mathrm{h}^{-1}$. Conditions: $10 \mathrm{~g} \mathrm{~L}^{-1}$ goethite, $0.01 \mathrm{M} \mathrm{NaClO}_{4}$, $5 \mathrm{mM}$ MES, pH 5. ${ }^{b}$ Data from Cheah et al. (15). ${ }^{c}$ Average $\mathrm{CV}=11 \%$ for samples S1-S4. ${ }^{d}(\cdots)=$ not measured.

DFO-B concentration increased, exceedingly so for sample S4 $(x=0.1)$. The more modest enhancement for the lesssubstituted samples (S1-S3) is in keeping with available Fe release data for unsubstituted goethite (15), which showed an increase in $\mathrm{R}_{\mathrm{DFO}}^{\mathrm{Fe}}$ from 11 to $20 \mathrm{nmol} \mathrm{g}^{-1} \mathrm{~h}^{-1}$ with an increase in [DFO] $]_{0}$ from 20 to $80 \mu \mathrm{M}$ (Table 2 and Figure 2).
TABLE 3. Steady-State Oxalate-Promoted Dissolution Rates ${ }^{\text {a }}$

\begin{tabular}{cccccc} 
& \multicolumn{5}{c}{ sample } \\
\cline { 2 - 6 }$[\mathbf{0 x}]_{0}(\boldsymbol{\mu M})$ & unsubstituted $^{b}$ & $\mathbf{S 1}^{c}$ & $\mathbf{S 2}^{\boldsymbol{c}}$ & $\mathbf{S 3}^{c}$ & $\mathbf{S 4}^{c}$ \\
20 & 0 & 0.7 & 0.8 & 0.5 & 0.3 \\
50 & $0.5^{d}$ & 0.1 & 0.1 & $\ldots$ & $\ldots$ \\
100 & 5.2 & $<0.1$ & 0.1 & 2 & 3 \\
200 & 18 & 8 & 17 & 140 & 15 \\
500 & $50^{e}$ & 151 & 45 & 123 & 67 \\
1000 & $63^{e}$ & & & & \\
& $78^{f}$ & 99 & 143 & 83 & 67
\end{tabular}

${ }^{a} R_{\mathrm{Ox}}^{\mathrm{Fe}}$ in nmol g${ }^{-1} \mathrm{~h}^{-1}$. Conditions: $10 \mathrm{~g} \mathrm{~L}^{-1}$ goethite, $0.01 \mathrm{M} \mathrm{NaClO}_{4}$, 5 mM MES, pH 5. ${ }^{b}$ Data from Cheah et al. (15). ${ }^{c}$ Average CV $=20 \%$ for samples S1-S4. ${ }^{d}[\mathrm{Ox}]_{0}=40 \mu \mathrm{M} .{ }^{e}[\mathrm{Ox}]_{0}=800 \mu \mathrm{M} .{ }^{f}[\mathrm{Ox}]_{0}=1200$ $\mu \mathrm{M} .{ }^{g}(\cdots)=$ not measured.

For samples S1-S4, there was a tendency of the Fe release rate to plateau and even decrease with increasing [DFO $]_{0}$, the plateau occurring at higher concentrations as the Al content of the sample increased (Figure 2). This same tendency to plateau was observed by Cheah et al. (15) for Fe release from unsubstituted goethite by DFO-B, for which a plateau was achieved when $[\mathrm{DFO}]_{0}=20 \mu \mathrm{M}$. Congruency of their graphs of the mass-normalized dissolution rate and the surface excess of DFO-B plotted against [DFO], was interpreted by Cheah etal. (15) as evidencefor DFO-promoted dissolution. In the present experiments, the data in Table 2 suggest that a plateau in $\mathrm{R}_{\mathrm{DFO}}^{\mathrm{Fe}}$ occurs at [DFO $]_{0} \lesssim 100 \mu \mathrm{M}$, sometimes followed by a narrow plateau at $[\mathrm{DFO}]_{0} \lesssim 500$ $\mu \mathrm{M}$. The values of $\mathrm{R}_{\mathrm{DFO}}^{\mathrm{Fe}}$ for $[\mathrm{DFO}]_{0} \lesssim 80 \mu \mathrm{M}$ are substantially higher for $\mathrm{S4}$ than for unsubstituted goethite (Table 2; 15) and for samplesS1-S3, indicating significant accessibility of DFO-B to reactive Fe(III) centers on the mineral surface.

The data on oxalate-promoted dissolution (Table 3) present a different trend. Either an inhibitory effect or no effect of the ligand was observed at low concentrations ([Ox] $<200 \mu \mathrm{M}$ ), whereasenhanced dissolution occurred at higher concentrations. These results are comparable to those obtained for unsubstituted goethite (15), which show that the Fe release rate at $[\mathrm{Ox}]<200 \mu \mathrm{M}$ did not surpass $18 \mathrm{nmol}$ $\mathrm{g}^{-1} \mathrm{~h}^{-1}$, and increases in [Ox] from 200 to $2000 \mu \mathrm{M}$ led to a nonlinear increase in the Ferelease rate from 18 to $125 \mathrm{nmol}$ $\mathrm{g}^{-1} \mathrm{~h}^{-1}$. Within experimental precision, the values of $\mathrm{R}_{\mathrm{Ox}}^{\mathrm{Fe}}$ for $[\mathrm{Ox}]_{0}=1 \mathrm{mM}$ (bottom row) are mutually similar for all samples. Maurice et al. (8) also noted similar Fe release rates for unsubstituted and low-substitution Al-goethites $(x \leq 0.04)$ at $\mathrm{pH} 3$ in the presence of $1 \mathrm{mM}$ oxalate, but they found significantly greater extent of Fe release and greater oxalate adsorption by $\mathrm{Al}$-goethite containing $8.8 \mathrm{~mol} \% \mathrm{Al}$, which is comparable to the Al content of sample S4. The same trend with increasing Al content was seen by Maurice et al. (8) in absorbance measurements of the maximum population of siderophore-producing bacteria per unit surface area that weregrown in the presence of theAl-goethites. Growth curves and absorbance were similar if $\mathrm{x} \leq 0.04$, whereas growth peaked earlier and absorbance was higher for $x=0.088$. These differences were attributed to the presence of highly reactive $\mathrm{Fe}(\mathrm{III})$ centers on the surface of the Al-goethite with $\mathrm{x}=$ $0.088(8)$.

Our results thus far may be summarized by stating that both DFO-B and oxalate enhanced the rate of Fe release from Al-goethite but did not show a trend of decreasing dissolution rate with increasing Al substitution like that observed commonly for proton-promoted dissolution (see, e.g., column 6 in Table 1). At concentrations below or equal to $100 \mu \mathrm{M}$, DFO-B effected Fe release more than did oxalate, whereas above $100 \mu \mathrm{M}$ concentration, the same was clearly true only for sample S4 ( $x=0.1)$. At higher concentrations, DFO-promoted dissolution exhibited a "plateau effect" (2, $15,25)$ suggesting prior adsorption of the siderophore. 
TABLE 4. Observed ( $R^{\mathrm{Fe}}$ ) and Calculated $\left(\mathbf{R}^{\mathrm{Fe}}\right.$ Dissolution Rates in the Presence of DFO-B and Oxalate ${ }^{\text {DF }}$

\begin{tabular}{|c|c|c|c|c|c|c|c|c|}
\hline \multirow[b]{3}{*}[0\mathrm{x}]{$_{0}(\mu \mathrm{M})$} & \multicolumn{8}{|c|}{ sample } \\
\hline & \multicolumn{2}{|c|}{ S1 } & \multicolumn{2}{|c|}{ S2 } & \multicolumn{2}{|c|}{ S3 } & \multicolumn{2}{|c|}{ S4 } \\
\hline & obs & calc $^{c}$ & obs & calc $^{c}$ & obs & calc $^{c}$ & obs & calc \\
\hline $0^{b}$ & 11 & 11 & 9 & 9 & 33 & 33 & 92 & 92 \\
\hline 20 & 15 & 12 & 196 & 10 & 11 & 33 & 77 & 92 \\
\hline $50^{d}$ & 85 & 11 & 129 & 9 & 71 & 33 & 94 & 92 \\
\hline 100 & 134 & 11 & 76 & 9 & 52 & 35 & 84 & 95 \\
\hline 200 & 78 & 19 & 79 & 26 & 49 & 175 & 71 & 107 \\
\hline 500 & 87 & 162 & 153 & 54 & 106 & 156 & 54 & 159 \\
\hline 1000 & 60 & 110 & 320 & 152 & 167 & 116 & 92 & 159 \\
\hline
\end{tabular}

$a[\mathrm{DFO}]_{0}=40 \mu \mathrm{M} . R_{\mathrm{DFO}}^{\mathrm{Fe}}$ in units of $\mathrm{nmol} \mathrm{g}^{-1} \mathrm{~h}^{-1}$. Conditions: $10 \mathrm{~g}$ $\mathrm{L}^{-1}$ goethite, $0.01 \mathrm{M} \mathrm{NaClO}_{4}, 5 \mathrm{mM}$ MES, $\mathrm{pH}$. Average $\mathrm{CV}=11 \%$ for all samples. ${ }^{b}$ Data from the second row in Table 3. ${ }^{c}$ Sum of observed rate for $[\mathrm{Ox}]_{0}=0$ (first row) plus the appropriate rate in Table 4 at $[\mathrm{Ox}]_{0}$ $>0 .{ }^{d}$ In the presence of DFO $(40 \mu \mathrm{M})$ and oxalate $(50 \mu \mathrm{M})$, the observed and calculated dissolution rates of unsubstituted goethite (15) corresponds to 35.40 and $18 \mathrm{~mol} \mathrm{~g}^{-1} \mathrm{~h}^{-1}$, respectively.

Siderophore-promoted Fereleasegenerally increased with Al substitution, parallel to what has been observed in the dissolution of Al-goethite in the presence of siderophoreproducing bacteria (8) butopposite to what has been reported in the dissolution of Al-goethite $(x=0.05$ and 0.33$)$ in the presence of $\mathrm{Fe}(\mathrm{III})$-reducing bacteria (6).

Table 4 lists values of $\mathrm{R}_{\mathrm{DFO}-\mathrm{Ox}}^{\mathrm{Fe}}$ measured at $\mathrm{pH} 5$ in the presence of $40 \mu \mathrm{M}$ DFO-B and increasing concentrations of oxalate. These rate data showed no significant linear correlation $(P=0.05)$ with the corresponding values of $R_{0 x}^{\mathrm{Fe}}$ in Table 3. Thus, the presence of DFO-B was indeed important. There are also important trends with the extent of $\mathrm{Al}$ substitution. Sample S1 displayed a synergistic effect of the two ligands (i.e., $\mathrm{R}_{\mathrm{DFO}-\mathrm{Ox} \text { obs }}^{\mathrm{Fe}}>\mathrm{R}_{\mathrm{DFO}-\mathrm{Ox} \text { sum }}^{\mathrm{Fe}}$ ) for $[\mathrm{Ox}]_{0}$ in the midrange of concentrations studied, whereas sample S2 displayed synergism over the entire range of [Ox]0. Samples S3 and S4 displayed little or no synergism.

The adsorption isotherm for oxalate on unsubstituted goethite in the presence of $0.01 \mathrm{M} \mathrm{NaClO}_{4}$ and $5 \mathrm{mM}$ MES at pH 5 (15) shows a maximum oxalate surface excess of 42 mmol $\mathrm{kg}^{-1}$ for solution concentrations above $200 \mu \mathrm{M}$. Adsorption isotherms for oxalate on samples S1-S4 (data not shown) indicate, just as for unsubstituted goethite, substantial adsorption of oxalate over the range of [Ox] $]_{0}$ listed in Table 4. Cheah et al. (15) also reported that oxalate competes with DFO-B for sorption sites on the goethite surface, explained in part because of the larger size of DFO-B molecules ( $M{ }_{r}^{\text {DFO-B }}=561.7 \mathrm{Da}$ and $\mathrm{M}_{\mathrm{r}}^{\mathrm{Ox}}=56 \mathrm{Da}$ ), which restricts their access to the surface. The trends observed for the dissolution of samples S1 and S2 (Table4) in the presence of DFO and oxalate at concentrations below $200 \mu \mathrm{M}$ (perhaps as high as $500 \mu \mathrm{M}$ for S2) is worth noting since the typical concentrations of DFO-B and oxalatein natural soil solutions are al so below $200 \mu \mathrm{M}(9,26-28)$. The synergism found may be the combined result of the ability of oxalate to adsorb strongly at the goethite surface and promote Fe release, coupled with thehigh selectivity of DFO for Fe(III). Chemical speciation calculations for a mixed oxalate-DFO-B solution containing $\mathrm{Fe}(\mathrm{III})$ at $\mathrm{pH} 5$ (15) confirmed that practically all $\mathrm{Fe}(\mathrm{III})$ is in the form of $\mathrm{Fe}(\mathrm{HDFO}-\mathrm{B})^{+}$complexes. In this scenario, the $\mathrm{Fe}(\mathrm{III})$-oxalate formed following dissolution, primarilyas $\mathrm{Fe}\left(\mathrm{C}_{2} \mathrm{O}_{4}\right)_{3}{ }^{3-}(15)$, will likely release $\mathrm{Fe}^{3+}$ by ligand substitution with DFO-B, leading to the production of $\mathrm{Fe}(\mathrm{HDFO}-\mathrm{B})^{+}$and uncomplexed oxalate, which in turn, could adsorb to the goethite surface again. The efficiency of oxalate in serving as an Fe shuttlenonetheless may belimited by the number of $\mathrm{Fe}-\mathrm{OH}$ sites available for dissolution or the formation of $\mathrm{Fe}$-oxalate-DFO ternary complexes. For
TABLE 5. Steady-State Al Release Rates from Al-Goethite ${ }^{a}$

\begin{tabular}{llllll} 
& \multicolumn{5}{c}{ sample } \\
\cline { 2 - 6 } ligand & S1 & S2 & S3 & S4
\end{tabular}

$\begin{array}{lcccc}\text { none }^{a} & 1.6 \pm 0.2 & 1.8 \pm 0.3 & \ldots & \ldots \\ \text { DFO-B }^{b} & 1.0 \pm 0.4 & 1.2 \pm 0.3 & 1.7 \pm 0.4 & 2.2 \pm 0.9 \\ \text { oxalate }^{c} & 2.6 \pm 0.6 & 1.9 \pm 0.6 & \ldots & \ldots\end{array}$

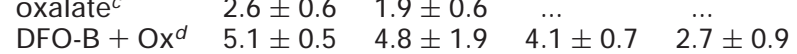

${ }^{a} R_{\mathrm{H}}^{\mathrm{Al}}$ in nmol g-1 $\mathrm{h}^{-1}$. Conditions: $10 \mathrm{~g} \mathrm{~L}^{-1}$ goethite, $0.01 \mathrm{M} \mathrm{NaClO}_{4}$, $5 \mathrm{mM}$ MES, pH 5. ${ }^{b} R_{\mathrm{DFO}}^{\mathrm{Al}}$ in $\mathrm{nmol} \mathrm{g} \mathrm{g}^{-1} \mathrm{~h}^{-1}, 20-1000 \mu \mathrm{M}$ DFO-B. ${ }^{c} R_{\mathrm{Ox}}^{\mathrm{Al}}$ in $\mathrm{nmol} \mathrm{g}^{-1} \mathrm{~h}^{-1}, 20-200 \mu \mathrm{M}$ Ox. ${ }^{d} R_{\text {DFO-Ox }}^{\mathrm{Al}}$ in $\mathrm{nmol} \mathrm{g}^{-1} \mathrm{~h}^{-1}, 40 \mu \mathrm{M}$ DFO-B, 20-200 $\mu$ M Ox. ${ }^{e}(\cdots)=$ not measured.

samples S3 and S4, synergism is not apparent, which may signal the effect of a decreased surface density of $\mathrm{Fe}-\mathrm{OH}$ sites (24). Predominance of oxalate over DFO-promoted dissolution of samples S3 and S4 is expected because of a low DFO surface excess (ca. $2.5 \pm 0.2 \mathrm{mmol} \mathrm{kg}{ }^{-1}$ ) and an increased oxalate adsorption with Al substitution for $x>$ 0.04 (8). These considerations imply that there are optimal combinations of ligand concentration and Al substitution that would lead to synergism between DFO-B and oxalate. Evidently, this combination was achieved for samples S1 and $\mathrm{S} 2$ in the present experiments.

Table 5 lists steady-stateAl release rates for the dissolution experiments whose results are described in Tables 2-4. If dissolution were congruent, then the Al release rate would scale with the Fe release rate as the ratio $x /(1-x)$. For the four Al-goethites investigated, this ratio is nominally 0.026 , $0.037,0.047$, and 0.11 , respectively. Comparison of the data in Table 5 with the corresponding Fe release rates in Tables 2-4 shows that the proton- and oxalate-promoted release rates for Al are more than an order of magnitude larger than what congruent dissolution would yield. The Al release rates for samples S1, S2, and S3 in the presence of DFO-B, however, areapproximately what congruent dissolution would provide $\left(R_{\mathrm{DFO}}^{\mathrm{Al}} / \mathrm{R}_{\mathrm{DFO}}^{\mathrm{Fe}}=0.025 \pm 0.008,0.030 \pm 0.014,0.036 \pm 0.016\right.$ respectively), whereas that for $\mathrm{S} 4$ is low $\left(\mathrm{R}_{\mathrm{DFO}}^{\mathrm{Al}} / \mathrm{R}_{\mathrm{DFO}}^{\mathrm{Fe}}=0.015\right.$ \pm 0.009 ). The comparison for $\mathrm{R}_{\mathrm{DFO}-\mathrm{Ox}}^{\mathrm{Al}}$ is roughly similar. Therefore, overall, DFO-B had theeffect of making Al-goethite dissolution more congruent than in the absence of ligand or in the presence of oxalate. We note in passing that samples S1 and S2 appear to show the same synergistic behavior for Al release as they exhibited for Fe release $\left(R_{D F O-O x}^{A l}>R_{D F O}^{A l}\right.$ $+\mathrm{R}_{\mathrm{Ox}}^{\mathrm{Al}}$ ).

As suggested by Bousserrhine et al. (6), not all the Al in Al-goethite may be in solid solution with $\mathrm{Fe}$, the possibility then being that gibbsite-likeinclusions or coatings may have formed instead, especially if $x>0.04(29,30)$. This would lend itself to differing response to protons and ligands as well as to facile secondary precipitation of Al released by the dissolution of any trueAl-goethitesolid solution. The stability constant for the 1:1 complex of Al with deprotonated DFO-B is significantly smaller than that of $\mathrm{Fe}(\mathrm{III})(15,31,32)$ :

$$
\begin{aligned}
\mathrm{M}^{3+}+\mathrm{DFO}^{3-}= & \mathrm{MDFO}^{0} \\
& \log \mathrm{K}_{\mathrm{M}}=28.6(\mathrm{M}=\mathrm{Fe}) \text { or } 23.8(\mathrm{M}=\mathrm{Al})
\end{aligned}
$$

The same trend holds for oxalate (33), but the difference in $\log K_{M}$ values is much smaller. These trends in log $K_{M}$ can be attributed to $\mathrm{Fe}^{3+}$ being a harder, more electronegative cation $(\chi=1.96)$ than $\mathrm{Al}^{3+}(\chi=1.61)$ and, therefore, more likely to form very stable complexes with either oxalate or DFO hard-O donor atoms $\left(\mathrm{O}_{\mathrm{L}}\right)$. Because $\mathrm{Al}^{3+}$ has the lower electronegativity, it is also likely to promote less electron delocalization along $\mathrm{O}_{\mathrm{L}}-\mathrm{Fe}-\mathrm{O}-\mathrm{Al}$ units and, therefore, a lower vicinal $\mathrm{Fe}-\mathrm{O}$ bond energy. 


\section{Acknowledgments}

The authors thank Dr. Kenneth Raymond, who kindly arranged for the sample of desferrioxamine-B; Calvin Tsao for the preparation of the Al-goethite samples; Paul Brooks, Andrew Yang, and Eduardo Domínguez for valuabletechnical assistance; and Sabine Goldberg (USDA-ARS) for the specific surface area data. This research was supported in part by the Director, Office of Energy Research, Office of Basic Energy Sciences, Geosciences Program, of the U.S. Department of Energy under Grant DE-FG03-96ER14667.

\section{Literature Cited}

(1) Cornell, R. M.; Schwertmann, U. The Iron Oxides: Structure, Properties, Reactions, Occurrence and Uses; VCH: Weinheim, 1996.

(2) Fitzpatrick, R. W.; Schwertmann, U. Geoderma 1982, 27, 335.

(3) Schwertmann, U.; Cornell, R. M. Iron Oxides in the Laboratory: Preparation and Characterization; VCH: Weinheim, 1991; pp $71-72$.

(4) Schwertmann, U. Plant Soil 1991, 130, 1.

(5) Torrent, J.; Schwertmann, U.; Barron, V. Clay Miner. 1987, 22, 329.

(6) Bousserrhine, N.; Gasser, U.; Jeanroy, E.; Berthelin, J. C. R. Acad. Sci. Paris, Earth Planet. Sci. 1998, 326, 617.

(7) Kukkadapu, R. K.; Zachara, J. M.; Smith, S. C.; Fredrickson, J. K.; Liu, C. Geochim. Cosmochim. Acta 2001, 65, 2913.

(8) Maurice, P. A.; Lee, Y.-T.; Hersman, L. E. Geochim. Cosmochim. Acta 2000, 64, 1363.

(9) Watteau, F.; Berthelin, J. Eur. J. Soil Biol. 1994, 10, 1.

(10) Kalinowsky, B. E.; Liermann, L. J.; Givens, S.; Brantley, S. L. Chem. Geol. 2000, 357.

(11) Kraemer, S. M.; Cheah, S.-F.; Zapf, R.; Xu, J.; Raymond, K. N.; Sposito, G. Geochim. Cosmochim. Acta 1999, 63, 3003.

(12) Holmén B. A.; Casey, W. H. Geochim. Cosmochim. Acta 1996, 60, 4403.

(13) Holmén, B. A.; Casey, W. H. Geochim. Cosmochim. Acta 1998, $62,726$.

(14) Eick, M. J.; Peak, J. D.; Brady, W. D. Soil. Sci. Soc. Am. J. 1999, $63,1133$.
(15) Cheah, S.-F.; Kraemer, S. M.; Cervini-Silva, J.; Sposito, G. Chem. Geol. (submitted for publication).

(16) Wolska, E.; Schwertmann, U. Neues Jahrb. Mineral. Montsh. 1993, 5, 213.

(17) Schwertmann, U.; Carlson, L. Soil Sci. Soc. Am. J. 1994, 58, 256.

(18) Schwertmann, U. Clay Miner. 1984, 19, 9.

(19) Kabai, J. Acta Chim. Acad. Sci. Hung. 1973, 78, 57.

(20) Schulze, D. G. Clays Clay Miner. 1984, 32, 36.

(21) Kraemer, S. M.; Hering, J. G. Geochim. Cosmochim. Acta 1997, 61, 2855.

(22) Bevington, P. R.; Robinson, D. K. Data Reduction and Error Analysisfor thePhysical Sciences; McGraw-Hill: New York, 1992.

(23) Schwertmann, U. Clay Miner. 1985, 20, 255.

(24) Ruan, H. D.; Gilkes, R. J. Clay Miner. 1995, 30, 55.

(25) Liermann, L. J.; Kalinowski, B. E.; Brantley, S. L.; Ferry, J. G. Geochim. Cosmochim. Acta 2000, 64, 587.

(26) Paterson, E.; Goodman, B. A.; Farmer, V. C. In Soil Acidity; Ulrich, B., Sumner, M. E., Eds.; Springer-Verlag: New York, 1991; pp 98-123.

(27) Vance, G. F.; Stevenson, F. J.; Sikora, F. J. In TheEnvironmental Chemistry of Aluminum; Sposito, G., Ed.; CRC Press: Boca Ratón, FL, 1996; pp 169-220.

(28) Fox, T. R.; Comerford, N. B. Soil. Sci. Soc. Am. J. 1990, 54, 1139.

(29) Ildefonse, Ph.; Cabaret, D.; Sainctavit, Ph.; Calas, G.; Frank, A.M.; Lagarde, P. Phys. Chem. Miner. 1998, 25, 112.

(30) Wolska, E. Adv. Geoecol. 1997, 30, 271.

(31) Albrecht-Gary, A.-M .; Crumbliss, A. L. Met. IonsBiol. Syst. 1998 35, 239.

(32) Desroches, S.; Biron, F.; Berthon, G. J. Inorg. Biochem. 1999, 5 , 27-35.

(33) Martell, A. E.; Smith, R. M.; Motekaitis, R. J. NIST Critically Selected Stability Constants of Metal Complexes Database; NIST: Gaithersburg, MD, 1998.

Received for review April 30, 2001. Revised manuscript received September 4, 2001. Accepted October 1, 2001. 